\title{
The role of precipitation, and petal and leaf infections in Sclerotinia stem rot of spring oilseed Brassica crops in Norway
}

\author{
Andrea Ficke • Chloé Grieu • May Bente Brurberg • Guro Brodal
}

Accepted: 8 August 2018 / Published online: 17 August 2018

(C) The Author(s) 2018

\begin{abstract}
Sclerotinia stem rot (SSR) is the most important disease of oilseed Brassica crops in Norway. Fungicide applications should be aligned with the actual need for control, but the SSR prediction models used lack accuracy. We have studied the importance of precipitation, and the role of petal and leaf infection for SSR incidence by using data from Norwegian field and trap plant trials over several years. In the trials, SSR incidence ranged from 0 to $65 \%$. Given an infection threshold of $25 \%$ SSR, regression and Receiver Operating Characteristics (ROC) analysis were used to evaluate different precipitation thresholds. The sum of precipitation two weeks before and during flowering appeared to be a poor predictor for SSR infection in our field and trap plant trials $(P=0.24, P=0.11$, respectively). Leaves from three levels (leaf one, three, five), and petals were collected at three to four different times during flowering from nine field sites over two years and tested for SSR infection with real-time PCR. Percentage total leaf and petal infection explained 57 and $45 \%$ of variation in SSR incidence, respectively. Examining the different leaves and petals separately, infection of leaf three sampled at full flowering showed the highest explanation of variation in later SSR incidence $\left(\mathrm{R}^{2}=65 \%, P<0.001\right)$. ROC analysis showed that given an infection threshold of $45 \%$, both petal and leaf infection recommended spraying when spraying was actually
\end{abstract}

\footnotetext{
A. Ficke $(\bowtie) \cdot$ C. Grieu $\cdot$ M. B. Brurberg $\cdot$ G. Brodal Norwegian Institute of Bioeconomy Research (NIBIO), Postbox 115, 1431 Ås, Norway e-mail: andrea.ficke@nibio.no
}

needed. Combining information on petal and leaf infection during flowering with relevant microclimate factors in the canopy, instead of the sum of precipitation might improve prediction accuracy for SSR.

Keywords Canola Rapeseed P Predictive factors . Receiver operator curve $\cdot$ Trap plants $\cdot$ Subarctica . Sclerotiorum $\cdot$ Real-time PCR

\section{Introduction}

Sclerotinia stem rot (SSR), caused by the ascomycete fungus Sclerotinia sclerotiorum (Lib.) de Bary and in some instances $S$. subarctica nom. prov. (Brodal et al. 2017; Taylor et al. 2018) is one of the major diseases in Brassica oilseed crops (Buchwaldt 2007). The disease symptoms include white-greyish lesions and bleaching on the main stem, often close to leaf petiole attachment sites. Severe infections cause premature ripening and sometimes lodging of the plants. Towards the end of the growing season, small, hard and melanized resting structures, called sclerotia develop within the stem. The sclerotia can survive for many years in the soil (Bolton et al. 2006) and are the major source of primary inoculum for SSR. Sclerotinia sclerotiorum has a wide host range of over 400 plant species (Boland and Hall 1994) and yield losses of up to 50-60\% have been recorded in oilseed rape (Pope et al. 1989; Nordin et al. 1992). Due to increased cropping and little rotation with non-SSR hosts in major oilseed Brassica production areas such as Germany and Canada, annual yield losses due to SSR 
are likely to increase and will require improved control methods (Derbyshire and Denton-Giles 2016).

Sclerotinia stem rot infection and disease development in oilseed crops is a multistep process. First, sclerotia of the fungus need to germinate in the soil, which requires a high soil moisture content and a certain temperature range (Clarkson et al. 2004). Once the sclerotia have germinated and the ascocarps have released their ascospores, the ascospores can survive and travel for an extended period of time (Clarkson et al. 2003), before they attach to tissue of its host crops. Only under high humidity (minimum 80 $86 \%$ ) or in the presence of free water, and at least $7^{\circ}-11^{\circ} \mathrm{C}$ (Koch et al. 2007), and nutritious tissue, such as flower petals (Jamaux et al. 1995), will the ascospores be able to germinate, penetrate and initiate infection. From this infected tissue, the pathogen can spread to the stem causing the characteristic symptoms of SSR in oilseed crops.

Management of SSR is mostly based on foliar fungicide applications during flowering (Bradley et al. 2006; Twengström et al. 1998) and cultural practices such as long-term rotation. Cost effective chemical control can only be achieved, if yield gains justify control costs. From studies of SSR in canola, Bom and Boland (2000) commented that outbreaks of SSR are sporadic and therefore difficult to control in a cost effective manner with routine fungicide sprays. Routine fungicide sprays during oilseed crop flowering in Germany were only cost effective in $33 \%$ of trials (Dunker and von Tiedemann 2004). Estimates of yield gain or the amount of yield loss avoided need to be based on a yield lossdisease relationship. Koch et al. (2007) determined the economic damage threshold for fungicide applications in winter oilseed rape in a comprehensive 3-year field trial in Germany. In their study, damage thresholds varied between 13 to $25 \%$ disease incidence, based on yield levels between 5 tons/ha and 3 tons/ha, respectively. In another study, $17 \%$ SSR incidence lead to a yield loss that would justify a fungicide application in USA (del Rio et al. 2007). A damage threshold of $25 \%$ SSR seems therefore a practical consideration in areas with lower yield potential, such as Norway. In addition to the unstable economic return, routine spraying is not in line with the European Directive on Sustainable Use of Pesticides (European Union 2009). This directive aims to reduce pesticide use in agriculture by using various strategies including prediction models and management thresholds. Implementation of the European IPM directive is part of the Norwegian action plan on sustainable use of pesticides (Anonymous 2016).
A decision support for cost effective fungicide application to prevent SSR development requires accurate prediction of the final disease incidence prior to the appearance of symptoms at a time when application is still effective. This is considered to be at flowering (growth stage (GS) 60-69) for oilseed crops, as the density of the crop stand makes later applications unfeasible. Krüger (1975) was one of the first to attempt identifying the predictive factors for SSR and found that germinating sclerotia and ascospore discharge during the season in Germany were correlated with SSR infections. Nordin et al. (1992) observed that high rainfall during the summer correlated with ascocarp formation and high SSR incidence in rapeseed crops in Sweden and used sclerotia depots to monitor ascospore release periods and estimate SSR infection risk. Morrall et al. (1990) used percentage petal infestation with $S$. sclerotiorum in the crop stand to estimate low, medium and high risk for SSR infection in Canada. Supporting their findings, Turkington et al. (1991a) found a significant positive relationship between petal infection and SSR incidence. The strength of the relationship varied with location and year, but petal infection explained $30 \%$ of variation in SSR incidence in their Canadian study. In a later study, Turkington and Morrall (1993) included precipitation, crop density, mean crop height and mean leaf area index or mean percentage light penetration with petal infection to better predict SSR incidence, but the significance of the factors changed with location and year. Nevertheless, measurements of petal infestation during flowering were significantly related to final disease incidence in all four years of the study. Overall, Turkington et al. (1991a) found that forecasts from 1985 to 1990 based on early bloom petal infestation measurements were $73 \%$ accurate in terms of forecasting whether crops had $<20 \%, 20-40 \%$ or $>40 \%$ incidence. Twengström et al. (1998) developed a forecasting model (a risk point table) based on field specific factors and precipitation to predict SSR in Sweden by using logistic regression. The significant factors included rain in the last two weeks before flowering, cropping and disease history of the field, weather forecasts and regional risk for apothecia development. The model was tested over two years and predicted the need for fungicide application correctly in $75 \%$ of the fields, given a spraying threshold of 25\% SSR incidence (Twengström et al. 1998). Bom and Boland (2000) tested petal infection, rainfall, soil moisture, plant height, canopy density and growth stage as determining factors for SSR over several weeks before 
and during flowering of canola in Canada, but none of the tested variables were strongly correlated with SSR incidence using linear and non-linear regression analysis. However, categorizing disease incidence in high and low SSR fields, showed weekly rainfall, soil moisture, crop height, percentage of petal infestation and the amount of apothecia being significantly associated with SSR within and between years. The authors showed that setting the critical value of petal infection at $45 \%$ lead to the highest accuracy of prediction, but still included too many false negatives. Combining petal infections with soil moisture improved prediction of SSR by 10 to $85 \%$ compared with the model only including petal infections. However, accuracy depended on the timing of soil moisture measurements and soil moisture itself (Bom and Boland 2000). A few years later, Koch et al. (2007) developed a crop loss-related forecasting model for SSR in Germany, called SkleroPro based on infection hours, defined as hours with at least $7-11^{\circ} \mathrm{C}$, above $80 \%$ relative humidity after late bud stage (GS 58). Infection hours above $23 \mathrm{~h}$ after GS 58 correlated well with high SSR incidence (Koch et al. 2007). The predicted disease risk or infection hours were then compared with a field specific damage threshold for SSR. A fungicide application was recommended when the predicted risk for SSR exceeded the economic threshold. Evaluation of the model showed that the model correctly recommended fungicide application in $81 \%$ of the fields evaluated in Germany (Koch et al. 2007).

Makowski et al. (2005) compared three different risk factors for SSR based on 85 field trials in France. These risk factors included percentage flower infection, an algorithm combining different field specific characteristics, such as level of infection in the last susceptible crop, and an algorithm combining weather factors such as precipitation in the last month before flowering. Their receiver-operator characteristic (ROC) curve analysis showed that percentage infected flowers was a better predictor for SSR than the other two algorithms (Makowski et al. 2005).

Most of the models described above, have been evaluated under Danish conditions between 1998 and 2006 (Jensen 2010). This study concluded that none of the currently used SSR prediction models, the risk point table, the apothecia depot, the flower petal infection method, nor ScleroPro would be suitable for the Danish decision support system, as oilseed growers expected correct prediction of SSR to be over $70 \%$ in order to use the prediction model in question (Jensen 2010).
In Norway, the risk point table (Twengström et al. 1998) was implemented into the Norwegian forecasting system VIPS (https://www.vips-landbruk.no/) to guide farmer's decisions on fungicide use against SSR in oilseed crops many years ago. Due to the variable effects of fungicide sprays on yields, we needed to evaluate the risk point table and investigate potential factors to forecast SSR risk and consequently the need for fungicide sprays. Therefore, the objectives of our current study were to determine the role of 'precipitation over the two week period prior to and during flowering', which is part of the risk point table, and to evaluate the factors 'petal infection' and 'leaf infection', in predicting the need for fungicide applications. These factors were chosen based on their relevance to SSR epidemiology and the data sets available for analysis.

\section{Materials and methods}

Field trials

Sclerotinia Stem Rot incidence data from 18 field trials, conducted between 2010 and 2016, located in different areas of southeastern Norway was used to relate SSR incidence to the sum of daily precipitation over two weeks preceding and including flowering (GS 60-69) (Table 1). The trials were located close to one of the following weather stations, provided by Agrometeorology Norway (http://lmt.nibio.no); Øsaker, Ås, Årnes, Gran, Ramnes, Hønefoss and Skjetten (Table 1). From the database Nordic Field Trials System (NFTS) (https://nfts.dlbr.dk), we selected datasets that contained information about the location, type of oilseed crop, date of sowing and flowering and SSR incidence. SSR incidence was measured as the percentage oilseed stems showing SSR symptoms per $\mathrm{m}^{2}$ at ripening (growth stage (GS) 80-90). Each field consisted of three to four replicates to determine the average field level of SSR.

\section{Trap plants}

Plants were grown by placing five seeds in plastic pots (20 $\mathrm{cm}$ in diameter) filled with potting soil (Degernes G'jord, from Degernes Vekstjord, Norway). Spring oilseed rape (Brassica napus) cv. Mosaik was used in our studies. This cultivar has been shown to be susceptible in commercial as well as in experimental fields and has also been used for greenhouse studies to follow 


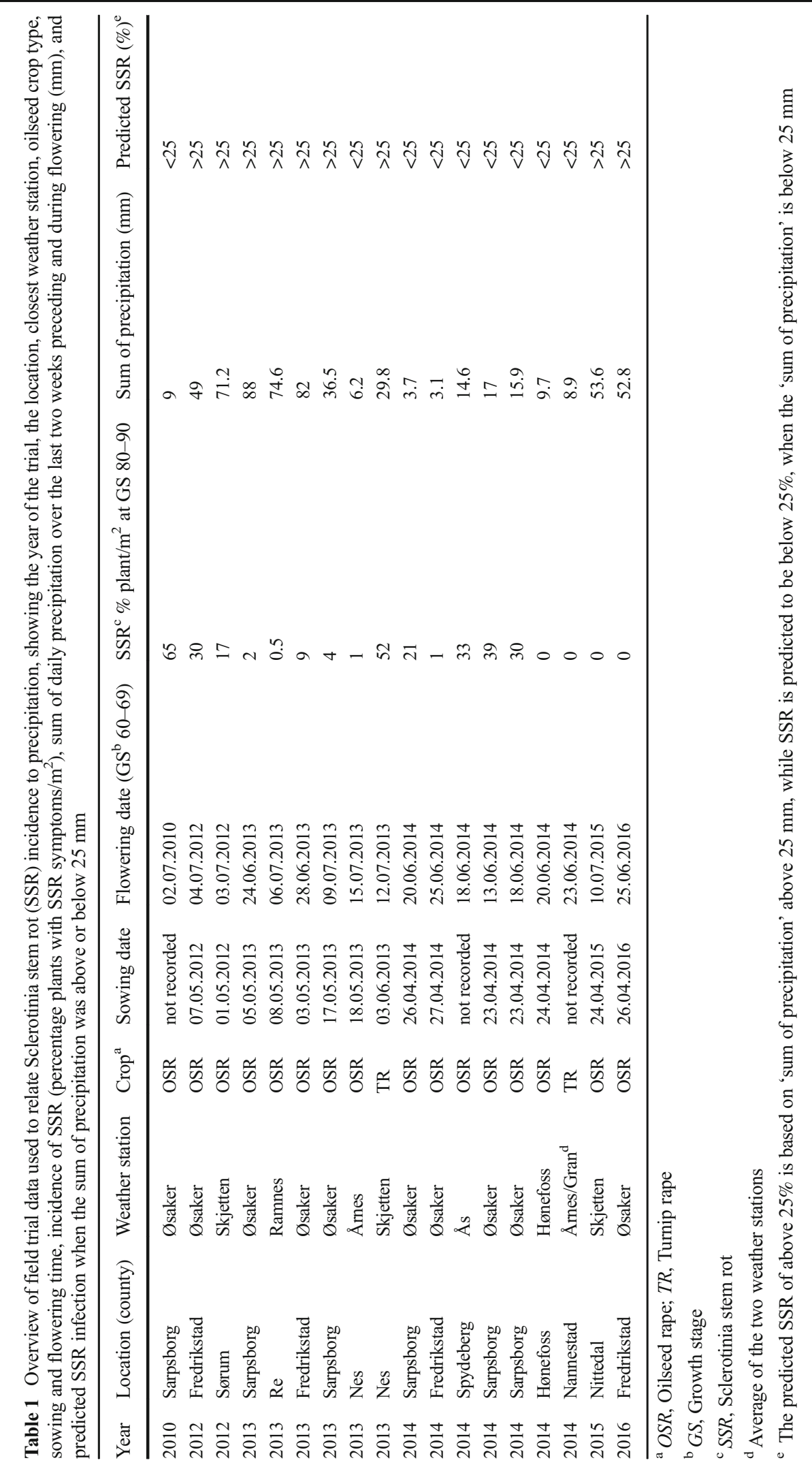


development of different S. sclerotiorum and $S$. subarctica isolates on the stem by our research team. In the following, we will refer to the causal agent as Sclerotinia spp. After seedling emergence, plants were thinned to three to four plants per pot. All plants were grown under a 16/8 h light/dark regime with Lucalox high pressure sodium vapor light bulbs minimum light quantity $150 \mathrm{mmol}, 18 / 15{ }^{\circ} \mathrm{C}$ at $50-75 \%$ relative humidity and watered regularly. Two to five pots with three to four healthy plants were transferred from the greenhouse once they had reached flowering stage (GS 6065 ) to the edge of spring oilseed fields or close (within $1 \mathrm{~m}$ ) to a known source of germinating sclerotia of Sclerotinia spp. One to three locations were selected each year in Southeastern Norway for this experiment (Table 2). We created the source of germinating sclerotia by burying sclerotia of five different Sclerotinia spp. isolates in the soil (1-3 cm deep) in a protected area in the autumn of 2013 at our research station in Ås (sclerotia depots). Ascocarp formation was followed during the season to confirm presence of ascospores for each year of the experiment by regular checks for apothecia development after precipitation events. During field exposure of one week, the rapeseed plants continued to flower, but started to shed their petals (late flowering (GS 69)). The experiment was conducted for five consecutive years (2013-2017). After a week of exposure in the field, trap plants were exchanged with new healthy flowering plants and the exposed plants incubated together with the non-exposed control plants in a climate room at $20-25{ }^{\circ} \mathrm{C}, 16 / 8 \mathrm{~h}$ light/darkness, $50-75 \%$ relative humidity. All plants were covered with plastic bags during incubation to ensure high humidity until they were assessed for SSR infection after two to three weeks. Absence or presence of SSR and percentage of SSR incidence was assessed per stem and stem infection per pot was averaged for each week. The sum of precipitation two weeks before and during exposure, obtained from the nearest weather station, was then related to SSR infection after incubation.

\section{Petal and leaf infection by Sclerotinia spp.}

Infection of leaves and flower petals of spring oilseed rape (B. napus) and turnip rape (B. rapa) was quantified by real-time PCR. Samples were collected from experimental field plots in Southeastern Norway once a week for three to four weeks at early flowering (GS 60), full flowering (GS 65) and late flowering (GS 69/70) during the summer in 2014 and 2015. In 2014 (Table 3A), four of the experimental fields were located in commercial spring oilseed fields (in the counties Re, Nannestad, Ullensaker and Sarpsborg) and one in a research field at NIBIO's experimental farm Apelsvoll (in the county Østre Toten). In 2015 (Table 3B), samples were taken from experimental field plots located in three commercial fields (in the counties Nittedal, Ullensaker and Sarpsborg) and in one research field at Apelsvoll (Østre Toten). Each experimental field had three or four replicates, except the research fields at Apelsvoll, where there were eight replicates. Six leaves of randomly chosen plants were sampled and pooled per replicate at each of three levels; lowest leaf (leaf one (L1)), third leaf (leaf three (L3)) and fifth leaf (leaf five (L5)) at each sampling time and location. One flower was collected from each of 20 randomly selected plants per replicate and pooled at each sampling time and location. Each pooled sample was put in a sealed plastic bag and stored at $-20{ }^{\circ} \mathrm{C}$. A subsample from each pooled leaf sample and 10 randomly chosen petals from each pooled flower sample, were taken for DNA extraction and further molecular analysis. SSR incidence was determined at ripening as described above.

\section{DNA extraction of leaves and flowers}

Leaf and petal samples were ground in liquid nitrogen and DNA was extracted according to the manufacturer's protocol (DNeasy Plant Mini-Kit, Qiagen). The quality of the DNA was assessed by an internal control (18S) during real-time PCR. Samples with poor DNA quality (18S Ct values $>20$ ) were purified using the NucleoSpin ${ }^{\circledR}$ Gel and PCR clean up kit (MachereyNagel). The samples showing poor DNA quality after purification were discarded.

\section{Real-time PCR}

Presence of Sclerotinia spp. in the samples was tested by a Taqman-real-time assay, essentially as described by Almquist and Wallenhammar (2015). The reaction mixture consisted of SsoAdvanced Universal Probes Supermix (Biorad), $0.2 \mu \mathrm{M}$ of each primer, $0.2 \mu \mathrm{M}$ of TaqMan probe and $2 \mu \mathrm{L}$ of DNA in a $25 \mu$ reaction volume. The real-time PCR was run on a C1000 Touch $^{\mathrm{TM}}$ CFX96 ${ }^{\mathrm{TM}}$ Real-Time System (Biorad) with cycling conditions as described by Almquist and Wallenhammar (2015). Three replicates of each DNA 


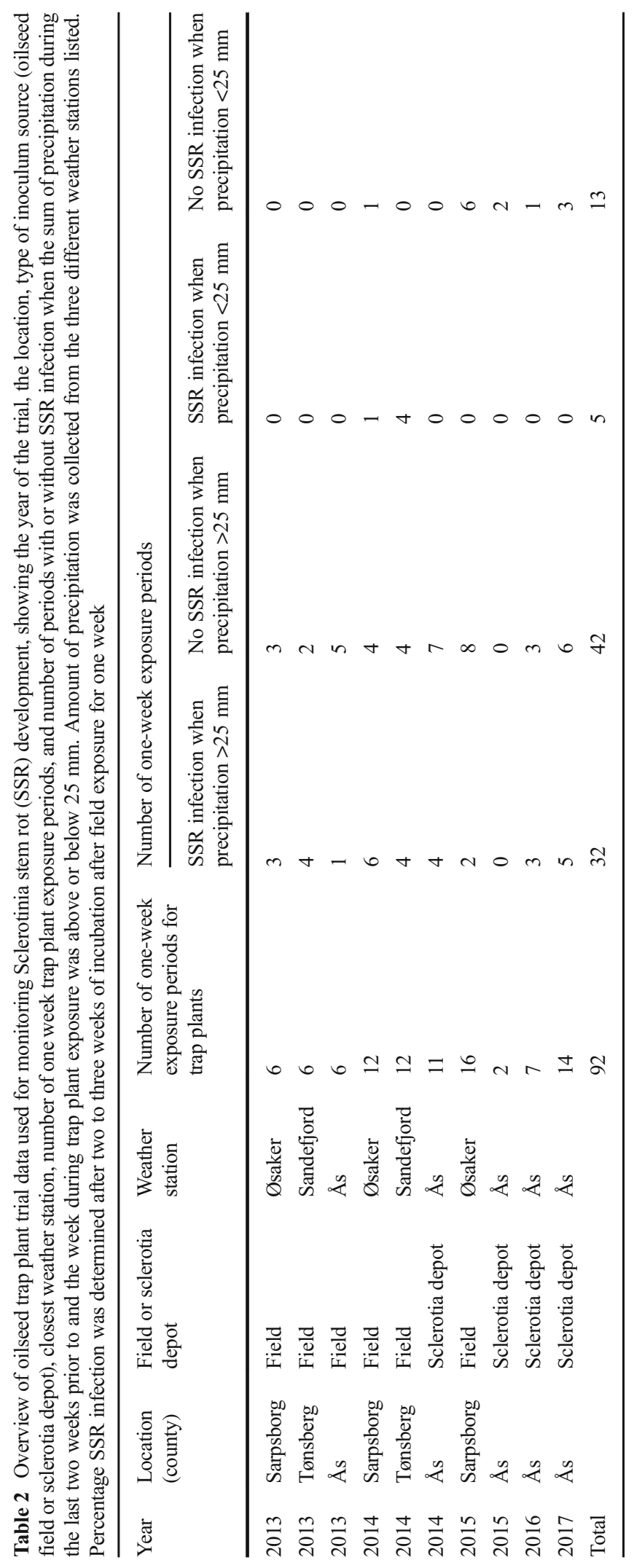




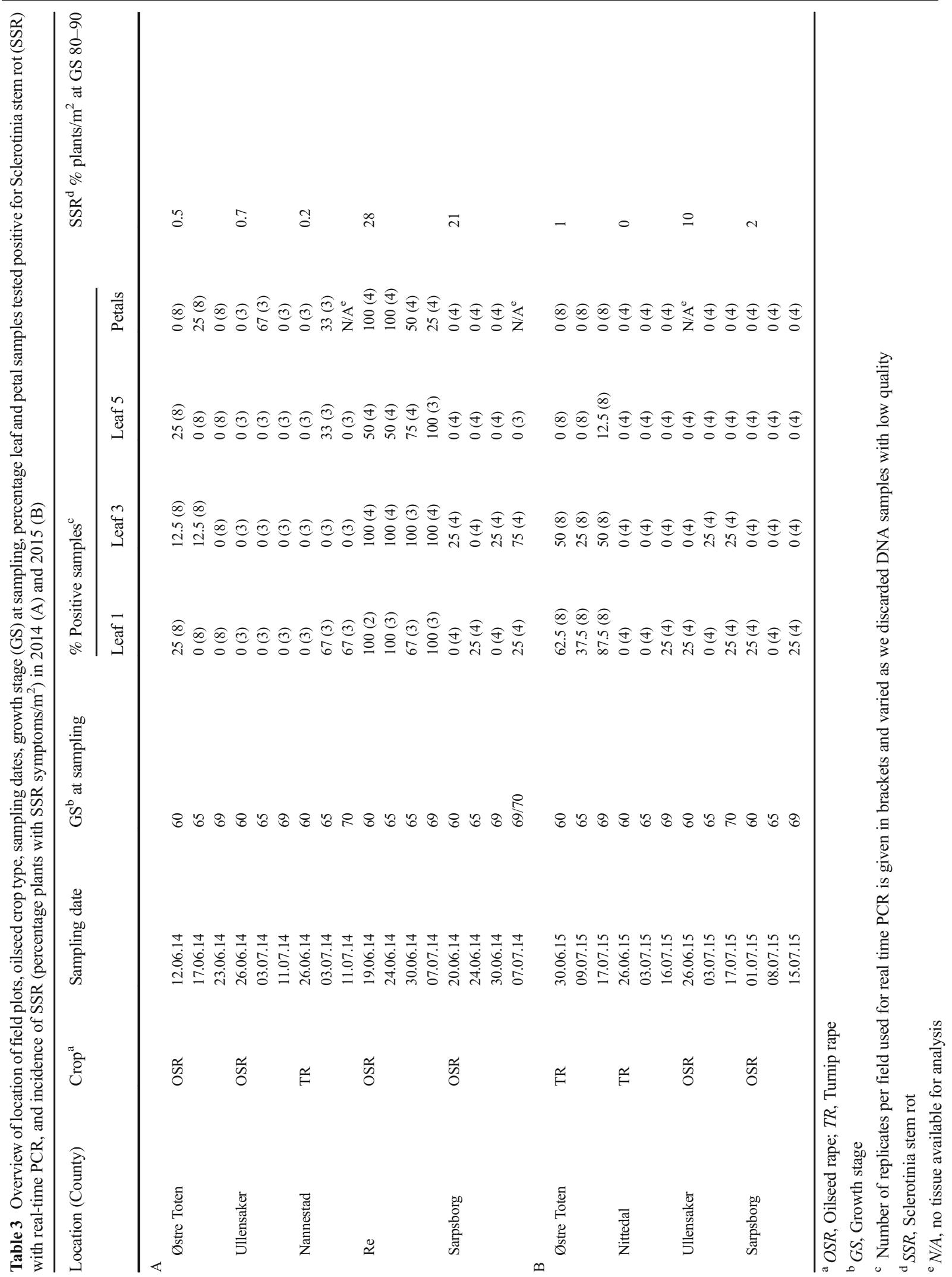


sample were tested. If at least two replicates of three were amplified by the PCR protocol, the sample was considered positive for Sclerotinia spp. Reference isolates of S. sclerotiorum and S. subarctica sequenced in 2013 at the University of Warwick, England, were used as positive controls (Brodal et al. 2017).

\section{Statistical analysis}

Regression analysis was used in Minitab 17.1.0 to analyze the correlation between precipitation and SSR incidence in field and trap plant trials, and between petal and leaf infections, and SSR incidence. The chosen spray threshold was $>25 \%$ SSR incidence, based on literature reviewed in the introduction. We used precipitation (threshold $>25 \mathrm{~mm}$ ) or petal/leaf infections (threshold $>45 \%$ positive samples, based on Bom and Boland (2000)) as the predictor and SSR incidence as the response factor. SSR infection was regressed with petal and leaf infections depending on sampling time (early, full and late flowering) and tissue type (leaf one (L1), three (L3), five (L5) and petals (P)). For the trap plant trials, we used binary logistic regression to determine if the sum of precipitation significantly influenced the absence or presence of SSR in trap plants. Logistic regression determines the likelihood of a binary outcome based on the predictive variables. In this case, the binary response was absence or presence of SSR in trap plants and the predictive variable was sum of precipitation. In addition, we performed a ROC analysis and determined the predictive value of precipitation for the field and trap plant trials using threshold values from 5 to $90 \mathrm{~mm}$ precipitation and $10-90 \mathrm{~mm}$ precipitation, respectively. We used several matrices to evaluate precipitation as a predictive factor for SSR incidence or need for fungicide applications (SSR $>25 \%$ at ripening) for the field trials and the trap plant data. One was the true positive rate, which is the number of fields that were correctly predicted to need fungicide applications divided by the total number of fields that needed fungicide applications (SSR >25\%); one was the false positive rate, which was determined by dividing the number of fields that were incorrectly predicted to need fungicide applications with the total number of fields that should not have been sprayed (SSR $<25 \%$ ); and one matrix was the false negative rate. The false negative rate was calculated by dividing the number of fields that were incorrectly predicted not to need spraying by the number of fields that should have been sprayed. The true positive rate is also referred to as a measure of the sensitivity of the chosen predictor at any given threshold and the false positive rate as the term describing the proportion of false alarms. The positive predictive value was used to evaluate the predictive factor and was derived by dividing the number of fields that needed to be sprayed and also are predicted in need of spraying, by the number of fields predicted in need of spraying.

\section{Results}

Field trials

The incidence of SSR in the 18 field trials we investigated varied between 0 and $65 \%$ (Table 1). The results showed a weak non-significant relationship between precipitation and SSR incidence. The regression equation was $S S R=23.91-0.2012 * P$, where $\mathrm{P}$ was the sum of daily precipitation over the two weeks preceding and including flowering ( $P$ value $=0.24$ and $\mathrm{R}^{2}=8.5 \%$ ) Based on our field trials, only two fields out of 18 (11\%) had precipitation above $25 \mathrm{~mm}$ and predicted SSR above $25 \%$, while it overestimated the risk of SSR being above $25 \%$ in $39 \%$ of the fields (seven out of 18 fields) (Table 1). In four out of 18 fields (22\%), precipitation underestimated the risk of SSR being over $25 \%$, while it correctly predicted SSR below $25 \%$ in five out of 18 fields (28\%). The true positive rate was $33 \%$ (two out of six fields) and the ROC curve showed that independent of the precipitation threshold, precipitation had a tendency for high false positive rate, or fall-outs (Fig. 1a), which means based on precipitation, SSR incidence was often predicted to be over $25 \%$, when it actually was below this spraying threshold. When changing the precipitation threshold from 5 to $90 \mathrm{~mm}$, ROC analysis showed that the positive predicted value varied between zero (threshold between 50 and $90 \mathrm{~mm}$ precipitation) and 0.42 (threshold $10 \mathrm{~mm}$ precipitation), while the true positive rate varied between zero and one, and the false negative rate varied between zero and 0.83 (Table 4A).

Trap plants

Linear regression analysis of trap plant data from 92 one-week exposure periods (cases) showed that SSR infection of the trap plants was poorly related to the sum of precipitation during two weeks before and the 
Fig. 1 Receiver operator characteristic (ROC) curve for true positive and false positive rates for precipitation as a predictor for fungicide spraying in the Sclerotinia stem rot (SSR) field trials (A) and on trap plants (B) at different precipitation thresholds. Highest threshold for spraying was $90 \mathrm{~mm}$ for the field trials (a) and $100 \mathrm{~mm}$ for the trap plants (b), lowest threshold was $5 \mathrm{~mm} \mathrm{(a)} \mathrm{and} 10 \mathrm{~mm}$ (b) of precipitation summed over the 2 weeks before and including flowering for field trials and trap plants, respectively. a

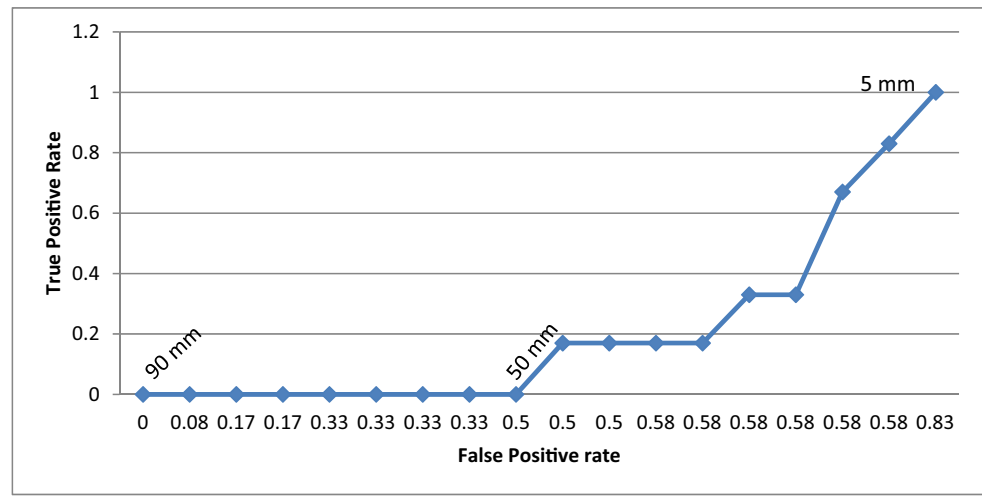

b

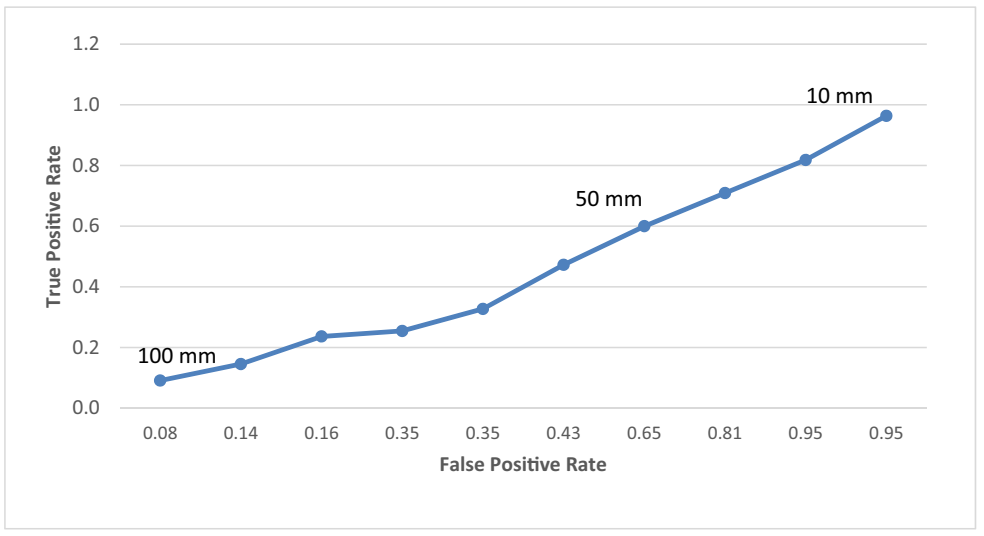

week plants were exposed to field conditions. The regression equation was $\operatorname{SSR} p=15.98+0.213^{*} \mathrm{P},(P$ val$\mathrm{ue}=0.11$ and $\mathrm{R}^{2}=42.8 \%$ ), where SSRp was the percentage stems per pot with SSR after field exposure and $\mathrm{P}$ the sum of precipitation two weeks before and during field exposure. Binary logistic regression also showed no effect of sum of precipitation on absence or presence of SSR in trap plants ( $\mathrm{P}$ value $=0.98, \mathrm{R}^{2}=0.0$ ). $\mathrm{ROC}$ analysis of trap plant data identified that the precipitation threshold of $25 \mathrm{~mm}$ during two weeks before and during exposure lead to $51 \%$ of wrongly predicted SSR cases (47 out of 92, see 'No SSR when precipitation $>25 \mathrm{~mm}$ 'plus 'SSR infection when precipitation $<25 \mathrm{~mm}$ 'in Table 2). Of those, 42 out of 47 cases were wrongly predicting SSR when SSR was not present (false positives). Based on the $25 \mathrm{~mm}$ threshold, $49 \%$ of the cases (45 out of 92) were correctly predicting presence or absence of SSR. Thirty-two out of 37 cases correctly predicted SSR infections in trap plants that actually had SSR (true positives), while 13 out of 55 cases correctly predicted the absence of SSR due to precipitation below $25 \mathrm{~mm}$ when there was actually no SSR present. The ROC curve showed that the false positive rate increased with the true positive rate as the threshold for the amount of precipitation decreased, indicating that the threshold amount of precipitation does not play an important role in reducing the false negative rate, or the fall-outs (Fig. 1b). When increasing the precipitation threshold from 10 until $100 \mathrm{~mm}$ the positive predictive value did not increase and varied between 0.32 ( $80 \mathrm{~mm}$ precipitation threshold) and 0.48 (70 $\mathrm{mm}$ precipitation threshold), the true positive rate varied between 0.08 and 0.96 and the false positive rate varied between 0.09 and 0.96 (Table 4B).

Petal and leaf testing

In 2014, two of the five tested oilseed field locations had an incidence of SSR above $20 \%$; Re (28\%) and Sarpsborg $(21 \%)$ (Table $3 \mathrm{~A})$. In contrast, at Nannestad, Ullensaker and Østre Toten, the incidence of SSR was below $1 \%$. Petal samples collected from 
Table 4 Precipitation thresholds $(\mathrm{mm})$ for spray recommendation against Sclerotinia stem rot (SSR), and number of oilseed fields out of 18 (A), and number of oilseed trap plant exposure cases out of 92 (B) that would have SSR, would not have SSR, would be predicted to have SSR or would not be predicted to have SSR by
Receiver operating characteristic (ROC) analysis. The positive predictive value (PPV), the true positive rate (TPR) and the false positive rate (FPR) is included as it changes with increasing precipitation threshold

\begin{tabular}{|c|c|c|c|c|c|c|c|}
\hline $\begin{array}{l}\text { Precipitation } \\
\text { threshold (mm) }\end{array}$ & Cases with SSR & Cases without SSR & $\begin{array}{l}\text { Predicted to } \\
\text { have SSR }\end{array}$ & $\begin{array}{l}\text { Predicted not } \\
\text { to have SSR }\end{array}$ & $\mathrm{PPV}^{\mathrm{a}}$ & $\mathrm{TPR}^{\mathrm{b}}$ & $\mathrm{FPR}^{\mathrm{c}}$ \\
\hline \multicolumn{8}{|l|}{ A } \\
\hline 5 & 6 & 10 & 16 & 2 & 0.38 & 1.00 & 0.83 \\
\hline 10 & 5 & 7 & 12 & 4 & 0.42 & 0.83 & 0.58 \\
\hline 15 & 4 & 7 & 11 & 7 & 0.36 & 0.67 & 0.58 \\
\hline 20 & 2 & 7 & 9 & 9 & 0.22 & 0.33 & 0.58 \\
\hline 25 & 2 & 7 & 9 & 9 & 0.22 & 0.33 & 0.58 \\
\hline 30 & 1 & 7 & 8 & 10 & 0.13 & 0.17 & 0.58 \\
\hline 35 & 1 & 7 & 8 & 10 & 0.13 & 0.17 & 0.58 \\
\hline 40 & 1 & 6 & 7 & 11 & 0.14 & 0.17 & 0.50 \\
\hline 45 & 1 & 6 & 7 & 11 & 0.14 & 0.17 & 0.50 \\
\hline 50 & 0 & 6 & 6 & 12 & 0.00 & 0.00 & 0.50 \\
\hline 55 & 0 & 4 & 4 & 14 & 0.00 & 0.00 & 0.33 \\
\hline 60 & 0 & 4 & 4 & 14 & 0.00 & 0.00 & 0.33 \\
\hline 65 & 0 & 4 & 4 & 14 & 0.00 & 0.00 & 0.33 \\
\hline 70 & 0 & 4 & 4 & 14 & 0.00 & 0.00 & 0.33 \\
\hline 75 & 0 & 2 & 2 & 16 & 0.00 & 0.00 & 0.17 \\
\hline 80 & 0 & 2 & 2 & 16 & 0.00 & 0.00 & 0.17 \\
\hline 85 & 0 & 1 & 1 & 17 & 0.00 & 0.00 & 0.08 \\
\hline 90 & 0 & 1 & 0 & 18 & 0.00 & 0.00 & 0.00 \\
\hline \multicolumn{8}{|l|}{ B } \\
\hline 10 & 35 & 53 & 88 & 4 & 0.40 & 0.96 & 0.96 \\
\hline 20 & 35 & 45 & 80 & 12 & 0.43 & 0.96 & 0.82 \\
\hline 30 & 30 & 39 & 69 & 23 & 0.43 & 0.81 & 0.71 \\
\hline 40 & 25 & 33 & 57 & 35 & 0.42 & 0.65 & 0.60 \\
\hline 50 & 16 & 26 & 42 & 50 & 0.38 & 0.43 & 0.47 \\
\hline 60 & 13 & 18 & 31 & 61 & 0.41 & 0.35 & 0.33 \\
\hline 70 & 13 & 14 & 27 & 65 & 0.48 & 0.35 & 0.25 \\
\hline 80 & 6 & 13 & 19 & 73 & 0.32 & 0.16 & 0.24 \\
\hline 90 & 5 & 8 & 13 & 79 & 0.38 & 0.14 & 0.15 \\
\hline 100 & 3 & 5 & 8 & 84 & 0.38 & 0.08 & 0.09 \\
\hline
\end{tabular}

${ }^{\mathrm{a}}$ The positive predictive value (PPV) is the number of cases with sclerotinia stem rot (SSR) divided by the number of cases predicted to have SSR

${ }^{\mathrm{b}}$ The true positive rate (TPR) is the number of cases predicted to have SSR divided by the total number of cases with SSR

${ }^{\mathrm{c}}$ The false positive rate (FPR) is the number of cases predicted not to have SSR divided by the total number of cases that had no SSR

Re at all collection dates; early (GS 60), full (GS 65), and late flowering (GS 69/70) tested positive for Sclerotinia spp. with real-time PCR (Table 3A). Otherwise, the fungus was detected in petal samples only at full flowering in Nannestad, Ullensaker and Østre Toten in 2014. Infected leaf samples were found in all locations except Ullensaker. Flowering time varied from location to location and lasted about two to three weeks (Table 3A).
In 2015, the field in Ullensaker had 10\% SSR, while Sarpsborg had 2\%, Østre Toten 1\% and Nittedal 0\% SSR infection (Table 3B). No petal infections were detected in any of the fields at any sampling time in 2015, and no infections of leaf five except in Østre Toten at late flowering (Table 3B). However, the pathogen was detected on leaf one and/ or leaf three at all locations. Flowering time in 2015 also varied from location to location, but generally 
a

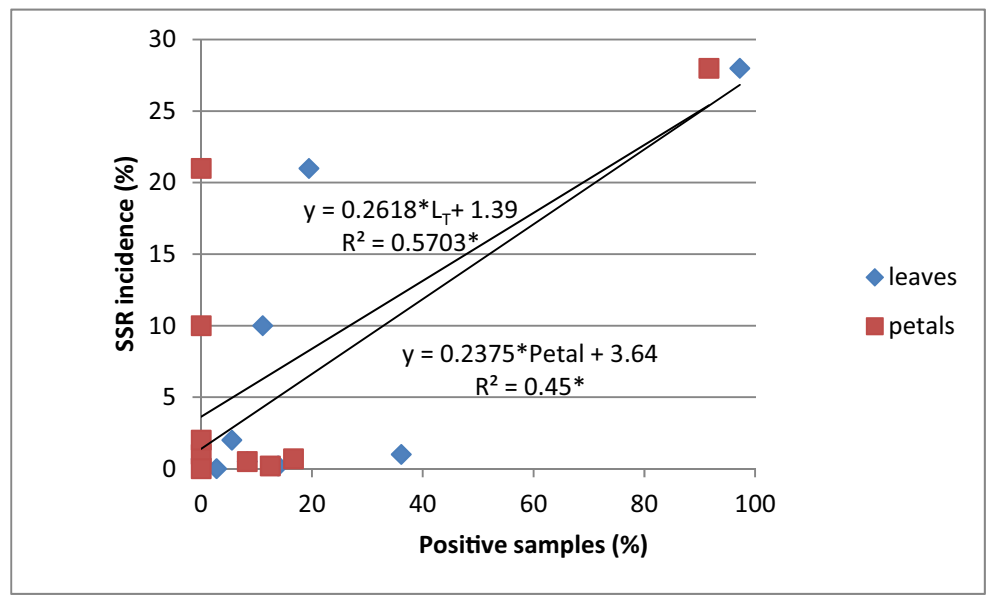

b

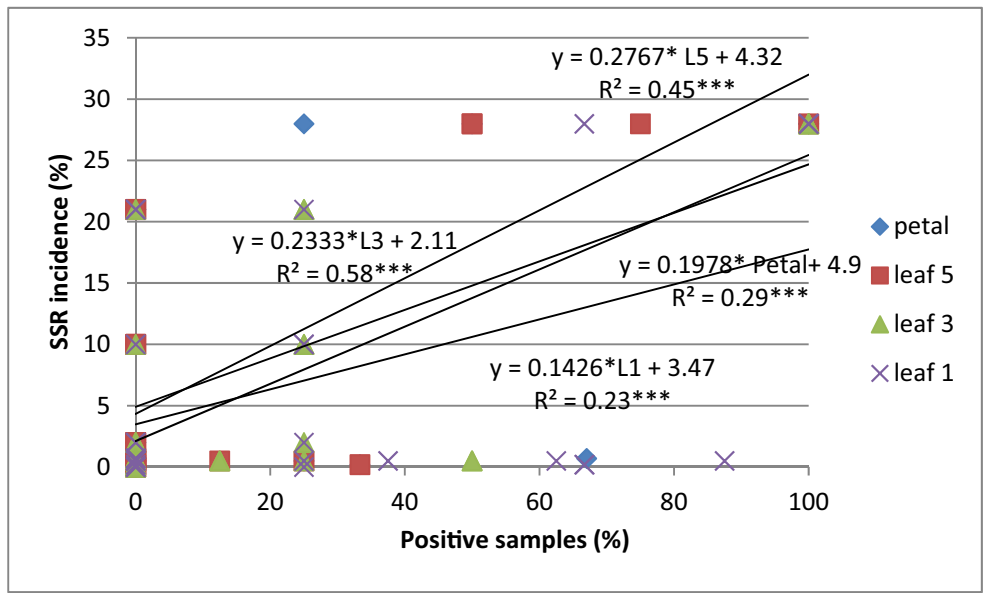

Fig. 2 Percentage Sclerotinia stem rot (SSR) infection of stems in the field related to leaf and petal infections as determined by realtime PCR. Regression of percentage positive samples from all leaves combined and petals for all sampling times and SSR incidence (a), from leaf one (L1), three (L3), five (5) and petals (P), and SSR incidence in the field, when all sampling times were

started later than in 2014 and lasted two to three weeks (Table 3B).

Regression analysis of percentage infected petal and leaf samples during the entire sampling period from all leaf levels combined showed that $45 \%$ of the variation in SSR incidence at ripening could be explained by petal infection and $57 \%$ by leaf infection (Fig. 2a). The regression equations were $\%$ SSR $=$ $1.39+0.2618$ leaves $(P=0.019)$ and $\% \mathrm{SSR}=3.64+$ 0.2375 petals $(P=0.048)$ for leaves and petals respectively (Fig. 2a). SSR incidence had a significant positive relationship with positive samples from leaf one, leaf three, leaf five, and petals (Fig. 2b). When combined (b), when sampled at early flowering (GS 60)(c), when sampled at full flowering (GS 65) (d) and when sampled at late flowering (GS 69/70 (e). Statistical significance is indicated as non significant $\left({ }^{\mathrm{NS}}\right)$ when $p>0.05$ and significant: * when $p<0.05$, ** when $p<0.01$, *** when $p<0.001$

we divided the different sample types (petal, leaf one, leaf three and leaf five) according to the sampling time, leaf one was no longer significant when sampled at early flowering (Fig. 2c) and late flowering (Fig. 2e). Leaf three was significantly related to SSR incidence at all sampling times (Fig. 2c, d, e) with the highest coefficient of correlation of $65 \%$ for leaf three sampled at full flowering (Fig. 2d). Petal and leaves sampled over a three to four week period and collected from different leaf levels explained 8-65\% percent of variation in SSR incidence in the nine fields tested, depending on the tissue sampled, the leaf level and time of sampling (Fig. 2b-e). There was 


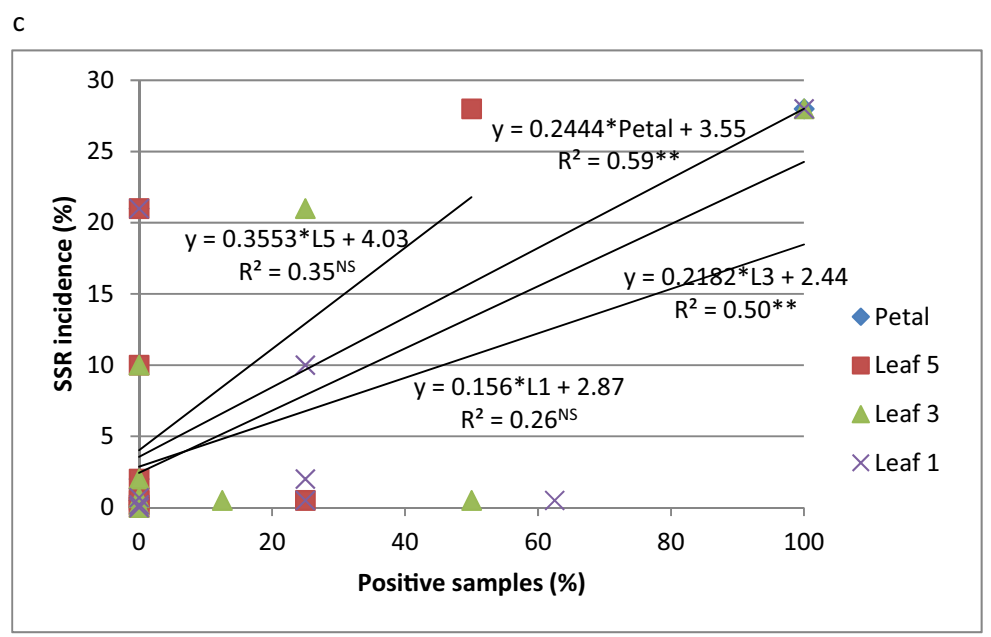

d

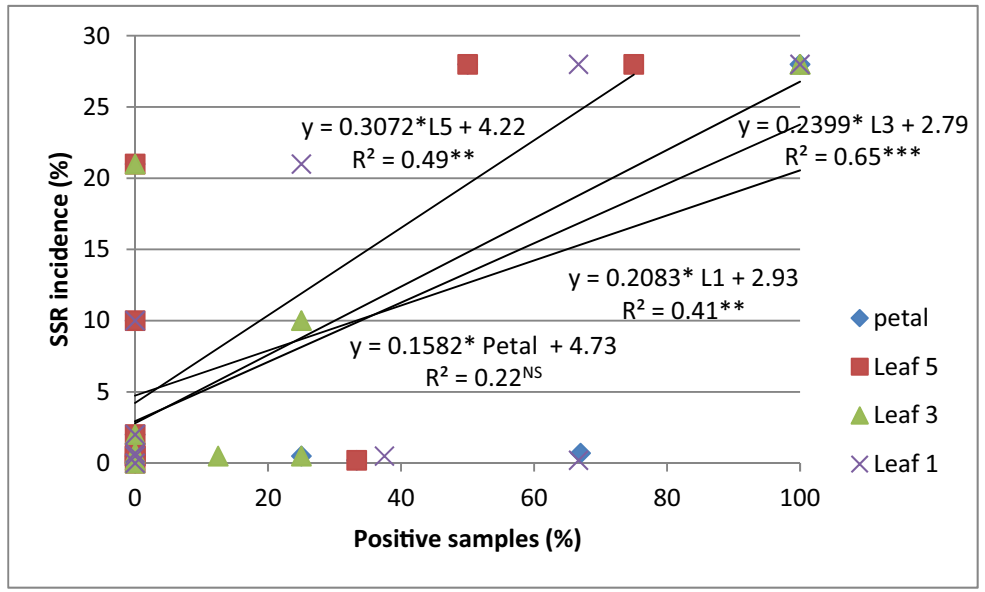

e

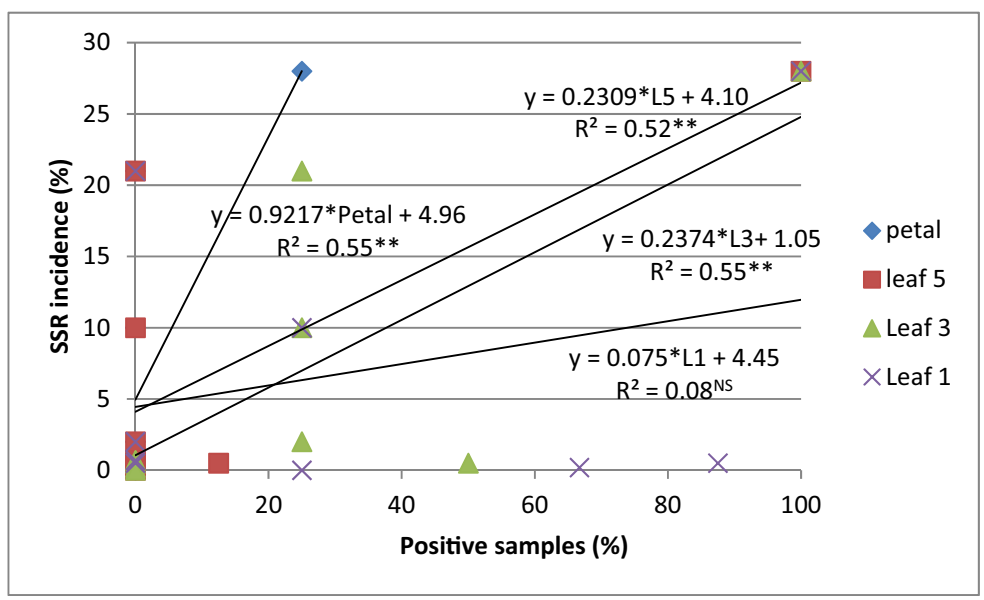

Fig. 2 (continued)

no significant interaction between year and tissue type sampled or with sampling time (data not shown).
During our trial period, only one field had an SSR infection of above $25 \%$ and would have been 
recommended for spraying, given a spray threshold of $25 \%$ SSR. ROC analysis showed that given a fungicide application threshold of $25 \%$ SSR incidence and a petal infection threshold of $45 \%$, petal infection correctly recommended fungicide spray when needed in $11 \%$ of the cases, and correctly predicted no need for fungicide prediction in $89 \%$ of the cases (Table 5). Given the same SSR incidence and leaf infection threshold for fungicide applications, percent infected leaves, independent of the leaf level would correctly predict the need for fungicide application just as well as petals did (Table 5).

\section{Discussion}

Limited use of available decision support models to guide fungicide application in farmers' fields is a major challenge for successful adoption of IPM measures. In Norway, oilseed crop cultivation, dominated by spring oilseed crops is limited by short and variable growing seasons, but also by pests and diseases. The use of the current risk point table available at the Norwegian decision support platform VIPS (https://www.vips-landbruk.no/) to assess the need for fungicide applications against SSR has been questioned by farmers and the Norwegian agricultural extension services due to uncertain prediction accuracy. Our objectives with the work presented here, were to understand the role of precipitation prior to and during flowering and the role of petal and leaf infections in predicting SSR. To test precipitation or its predictive strength in determining the risk for SSR, we used data from 18 field trials and supplemented our study on the role of precipitation by identifying infection periods based

Table 5 Receiver operator characteristic (ROC) analysis of using percentage leaf and petal infection tested with real-time PCR as predictors for Sclerotinia stem rot (SSR) above 25\%. Recommended fungicide spray or not recommended spray is based on a $45 \%$ infection threshold for petals and leaves. In our nine field trials, only one had an SSR incidence of over $25 \%(11 \%)$ and leaves as well as petals showed over $45 \%$ infection based on real-time PCR (spray recommended), while eight fields had an SSR incidence of below $25 \%$ ( $89 \%$ of the fields) and less than $45 \%$ of leaves and petals were infected based on real-time PCR (spray not recommended)

\begin{tabular}{lll}
\hline & Rec. spray & Not rec. Spray \\
\hline$>25 \%$ SSR & 11 & 0 \\
$<25 \%$ SSR & 0 & 89 \\
\hline
\end{tabular}

on trap plants that were exposed to field conditions and correlated precipitation during the exposure period with infection success. Based on our results, we conclude that precipitation alone is a poor predictor for SSR incidence in Norway, despite the known need for leaf wetness or high humidity for SSR infection (Clarkson et al. 2014). The microclimate in the canopy might not be well reflected by precipitation measurements from weather stations kilometers distant from the plots investigated. Leaf wetness and humidity measured directly in the canopy, where the pathogen infects and establishes might better correlate with SSR incidence, than precipitation registered in the general area.

The poor relationship between precipitation and SSR incidence in the field, could also be partly due to our disease assessment method. Determining infection was based on white-greyish lesions and bleaching, which could sometimes be misleading, as early maturation or other stress factors could increase senescing and thus bleaching of the stems, ultimately interfering with the correct assessment of SSR. The use of trap plants to determine SSR infection periods has its limitations, as the microclimate in the canopy of an oilseed crop field and the canopy of three to four plants arranged in two to five pots at the edge of a field, is likely to be very different. However, we would still expect an association between precipitation and SSR infection in trap plants, given precipitation does play a significant role in larger oilseed crop fields. In our field trials and trap plant experiments, precipitation overestimated the need for fungicide applications. The poor relationship between precipitation and SSR incidence does not mean that precipitation is not important for SSR in Norway. However, given the Norwegian climate and cropping practices, availability of primary inoculum might be more limited in Norway than in areas with more intense oilseed cropping, such as Sweden, where precipitation appeared more important (Twengström et al. 1998). The arable land in the South Eastern part of Norway is mostly used for cropping barley, wheat and oats, and long-term rotation between spring oilseed crops (five to seven years) is common practice. Countries with intense oilseed production are more likely to have an omnipresent primary inoculum, as sclerotia can survive for many years in the soil (Bolton et al. 2006) and ascospores can travel over distances of at least 100-300 m (Ben-Yephet and Bitton 1985; de Jong et al. 2002) enabling the fungus to invade adjacent fields. With sufficient inoculum present, precipitation or infection hours are more 
likely to be the most important predictors for disease incidence, than in areas where inoculum is sporadic, such as the Southeast of Norway. Final disease levels will not only depend on leaf wetness, humidity or precipitation during the season, but will also depend on the amount of inoculum available. Thus, prediction of SSR will need to consider inoculum availability, e.g. the amount of germinating sclerotia and the frequence of ascospores discharge during the most susceptible phase of plant development.

In our study, infected leaves and petals were chosen as predictive factors because the ascospores of the pathogen need tissue that is easily penetrated to obtain nutrients and develop secondary hyphae that can then penetrate the more waxy stems of the oilseed crops (Jamaux et al. 1995). The role of infected leaves and petals in predicting SSR varied greatly in our study depending on GS at sampling time. Infection of leaf three sampled at full flowering showed the highest explanation of variation in later SSR incidence. Almquist and Wallenhammar (2015) reported significantly higher incidences of SSR on leaves at lower canopy levels, than on higher levels. Moreover, they detected the pathogen on leaves and not on petals in one field experiment, with a corresponding stem rot incidence of $7 \%$, which suggested that leaves could be an important entry port for Sclerotinia spp. ascospores. Similarly, we detected Sclerotinia spp. only in leaves and not in petals in the 2014 field at Sarpsborg, where SSR incidence was $21 \%$. Leaves could serve as an alternative entry route for SSR, as senescent leaves might be easier to penetrate by germinating ascospores and provide suitable nutrition for the pathogen. However, it could also be due to variation in petal infections during the flowering period. Infected petals that are already shed and caused leaf infection are not available anymore for SSR detection and would not be included in the sampling. In their review, Derbyshire and Denton-Giles (2016) commented that high infection rates of green leaves were somewhat surprising, although as the authors suggested in the same study, senescing leaves could be an alternative nutrient source for ascospores and could constitute an entry route for SSR infections.

Sampling time was not a significant factor in our study, but sampling at full flowering improved the relationship between infections of leaf three and final SSR incidence from 50 to $65 \%$ (Fig. 2b-d), which suggests fluctuations in infection events during flowering. These fluctuations could be due to ascospore availability and weather conditions. Turkington et al. (1991b) observed that the diurnal pattern of mean percentage petal infestations was less pronounced because petal infections did not only reflect the most current infection event, but the sum of infection events over the last few days, as the petals can remain in the inflorescence for almost a week. This means that the leaf infections we have observed could be the cumulative result of successive shedding of previously infected petals, even though we did not find infected petals at the time of sampling. The role of sampling time needs to be investigated further as there are likely to be differences in infection periods from year to year. Infection periods do not only depend on the release of ascospores and availability of suitable host tissue but also on conducive weather conditions. Previous work by Gugel and Morrall (1986) included agar plating of leaf axils and bases in addition to petal samples, but the authors decided to focus on collection of live and dead petals, because leaf tissue samples were more time consuming and difficult to collect and provided information already offered by the petal samples. They also suggested that leaf tissues may be more prone to contamination from the soil, making identification of $S$. sclerotiorum from plated material more difficult. However, the use of PCRbased technologies as used in the current study would mitigate this risk. The significant role of leaf and petal infection in SSR prediction in our study might be due to the fact, that primary inoculum is more limited in Norway than in other countries, where agricultural areas are more often cropped with oilseed rape plants. In countries with omnipresent inoculum, the limiting factor for SSR is more likely precipitation or moisture than in countries with little inoculum available.

Given a spraying threshold of $45 \%$ infection for petal and leaf samples during flowering time, both petal and leaf infection determined the need for fungicide use (above 25\% SSR at ripening) very well (Table 5). Even though we used a relatively fast and simple method to determine infection by real-time PCR, the method is not suitable for large scale testing. The use of rapid petal and leaf testing kits to determine petal infections, such as commercialized in Australia (Derbyshire and DentonGiles 2016) are based on culture plates and might need to be substituted by a quantitative or real-time PCR based systems, such as those that detect aerial inoculum levels caught by spore traps in the SYield sensor system from Syngenta (Derbyshire and Denton-Giles 2016). PCR methods for petal and leaf infections, such as published by Ziesman et al. (2016), Reich et al. (2016) and Almquist and Wallenhammar (2015), should be adapted for large 
scale use to improve future SSR prediction in the field. Pre-infection treatment before full flowering with the commonly recommended protectant fungicides might be more effective against SSR and more feasible than applying the fungicides during full or late flowering, after determining the risk of infection based on leaf and/ or petal testing. However, Spitzer et al. (2017) reported no significant differences in the effectiveness of fungicides against SSR between application at early/full (GS 61-63) and full/late (GS 65-67) flowering. Earlier flowering varieties of spring or winter oilseed crops were used by Bečka et al. (2016) and showed that infection of petals sampled at full flowering from these early flowering crops could be used to determine the infection pressure of SSR in a given year to better evaluate the risk of SSR in the main crop. This would be especially relevant in regions where flowering time does not exceed two to three weeks and early fungicide sprays remain effective until the end of petal fall.

In agreement with previous studies (Turkington et al. 1991a; Bom and Boland 2000), petal infection appeared to play a role in determining the risk of SSR. In addition, we saw that percentage leaves infected with Sclerotinia spp. explained a substantial amount of SSR variation in the field, which supports the results of Almquist and Wallenhammar (2015). Including results from petal and especially leaf testing to estimate inoculum availability might significantly improve the performance of our currently used risk point table. Future studies could include testing leaves at earlier stages to investigate the effect of early leaf infection on SSR infection.

Integrating assessment of leaf and petal infections with micro-environmental conditions in the canopy, measured in infection hours, such as used by Koch et al. (2007), could also improve prediction of SSR development. However, deriving humidity or other microclimatic conditions in the canopy from ambient humidity, solar radiation and/or precipitation recorded by weather stations distant from the crop stand could be challenging and needs to be carefully tested in any future model. Moreover, in-crop monitoring of microenvironmental conditions may be more appropriate, especially given the commercial availability of low-cost data loggers that can be placed directly within a field.

Acknowledgements We would like to thank Monica Skogen and Jafar Razzaghian for their technical support in the laboratory, Andrew Dobson for growing and maintaining field plots and the plants for the trap plant trials, and Torfinn Torp for his valuable advice on the statistical analysis. We also would like to acknowledge the collaboration with the Norwegian Agricultural Extension Service (Norsk landbruksrådgiving) for their field work, and Unni Abrahamsen and Einar Strand for their valuable input and facilitation of data acquisition from NFTS. This work was mainly funded by the Foundation for Research Levy on Agricultural Products/Agricultural Agreement Research Fund (research grants 218896 and 244210) with additional funding from Felleskjøpet Agri, Norgesfôr/Strand Unikorn, Fiskå Mølle, Yara Norge, Tine, Bayer Crop Science, and Nibio.

\section{Compliance with ethical standards}

Conflict of interest The authors declare that they have no conflict of interest.

Open Access This article is distributed under the terms of the Creative Commons Attribution 4.0 International License (http:// creativecommons.org/licenses/by/4.0/), which permits unrestricted use, distribution, and reproduction in any medium, provided you give appropriate credit to the original author(s) and the source, provide a link to the Creative Commons license, and indicate if changes were made.

\section{References}

Anonymous (2016). Handlingsplan for bærekraftig bruk av plantevernmidler 2016-2020 [Action plan for sustainable use of pesticides 2016-2020]. Norwegian Ministry of Agriculture and Food, Norway. https://www.regjeringen. no/no/dokumenter/handlingsplan-for-barekraftig-bruk-avplantevernmidler-2016\%2D\%2D2020/id2485460/ Accessed September 2017.

Almquist, C., \& Wallenhammar, A.-C. (2015). Monitoring of plant and airborne inoculum of Sclerotinia sclerotiorum in spring oilseed rape using real-time PCR. Plant Pathology, 64, 109-118.

Bečka, D., Prokinová, E., Šimka, J., Chihlář, P., Bečková, L., Bokor, P., \& Vašák, J. (2016). Use of petal test in earlyflowering varieties of oilseed rape (Brassica napus L.) for predicting the infection pressure of Sclerotinia sclerotiorum (lib.) de Bary. Crop Protection, 80, 127-131.

Ben-Yephet, Y., \& Bitton, S. (1985). Use of a selective medium to study the dispersal of ascospores of Sclerotinia sclerotiorum. Phytoparasitica, 13, 33-40.

Boland, G. J., \& Hall, R. (1994). Index of plant hosts of Sclerotinia sclerotiorum. Canadian Journal of Plant Pathology, 16, 93-108.

Bolton, M. D., Thomma, B. P., \& Nelson, B. D. (2006). Sclerotinia sclerotiorum (lib.) de Bary: Biology and molecular traits of a cosmopolitan pathogen. Molecular Plant Pathology, 7(1), 1-16.

Bom, M., \& Boland, J. G. (2000). Evaluation of disease forecasting variables for sclerotinia stem rot (Sclerotinia sclerotiorum) of canola. Canadian Journal of Plant Sciences, 80, 889-898.

Bradley, C. A., Lamey, H. A., Endres, G. J., Henson, R. A., Hanson, B. K., McKay, K. R., Halvorson, M., LeGare, D. G., \& Porter, P. M. (2006). Efficacy of fungicides for control of Sclerotinia stem rot of canola. Plant Disease, 90, 1129-1134. 
Brodal, G., Warmington, R., Grieu, C., Ficke, A., \& Clarkson, J. P. (2017). First report of Sclerotinia subarctica nom. Prov. (Sclerotinis sp. 1) causing stem rot of turnip rape (Brassica rapa subsp. oleifera) in Norway. Plant Disease, 101, 386386.

Buchwaldt, L. (2007). Sclerotinia white mold (cabbage drop, stem rot, watery soft rot), In Rimmer, S. R., Shattuck, V. I., Buchwaldt (Ed), Compendium of brassica diseases (pp. 4347). St Paul, Minnesota, USA. The American Phytopathological Society: APS Press.

Clarkson, J. P., Staveley, J., Phelps, K., Young, C. S., \& Whipps, J. M. (2003). Ascospore release and survival in Sclerotinia sclerotiorum. Mycological Research, 107, 213-222.

Clarkson, J. P., Phelps, K., Whipps, J. M., Young, C. S., Smith, J. A., \& Watling, M. (2004). Forecasting Sclerotinia disease on lettuce: Toward developing a prediction model for carpogenic germination of sclerotia. Phytopathology, 94, 268-279.

Clarkson, J. P., Fawcett, L., Anthony, S. G., \& Young, C. (2014). A model for Sclerotinia sclerotiorum infection and disease development in lettuce, based on the effects of temperature, relative humidity and ascospore density. PLoS One, 9(4), e94049.

de Jong, M. D., Bourdôt, G. W., Hurrell, G. A., Saville, D. J., Erbink, H. J., \& Zadoks, J. C. (2002). Risk analysis for biological weed control - Simulating dispersal of Sclerotinia sclerotiorum (lib.) de Bary ascospores from a pasture after biological control of Cirsium arvense (L.) Scop. Aerobiologia, 18, 211-222.

del Rio, L. E., Bradley, C. A., Henson, R. A., Endres, G. J., Hanson, B. K., Mckay, K., Halvorson, M., Porter, P. M., Le Gare, D. G., \& Lamey, H. A. (2007). Impact of Sclerotinia stem rot on yield of canola. Plant Disease, 91, 191-194.

Derbyshire, M., \& Denton-Giles, M. (2016). The control of sclerotinia stem rot on oilseed rape (Brassica napus): Current practices and future opportunities. Plant Pathology, 65, 859-877.

Dunker, S., \& von Tiedemann, A. (2004). Disease yield loss analysis for Sclerotinia stem rot in winter oilseed rape. IOBC/wprs Bulletin, 27, 59-65.

European Union (2009). Directive 2009/128/EC of the European parliament and of the council of 21 October 2009 establishing a framework for community action to achieve the sustainable use of pesticides. Official Journal of European Union 52, 71-86, http://eur-lex.europa.eu/legal-content/ EN/TXT/?uri=OJ:L:2009:309:TOC. Accessed September 2017.

Gugel, R. K., \& Morrall, R. A. A. (1986). Inoculum-disease relationships in sclerotinia stem rot of rapeseed in Saskatchewan. Canadian Journal of Plant Pathology, 8, 89-96.

Jamaux, I., Gelie, B., \& Lamarque, C. (1995). Early stages of infection of rapeseed petals and leaves by Sclerotinia sclerotiorum revealed by scanning electron microscopy. Plant Pathology, 44, 22-30.

Jensen, P. H. (2010). Forecasting sclerotinia stem rot in oilseed rape (103 pp). Master thesis: Faculty of Life Sciences, University of Copenhagen.
Koch, S., Dunker, S., Kleinhenz, B., Röhrig, M., \& von Tiedeman, A. (2007). Crop-loss related forecasting model for Sclerotinia stem rot in winter oilseed rape. Phytopathology, 97, 11861194.

Krüger, W. (1975). Die Beeinflussung der Apothezien- und Askosporen-Entwicklung des Rapskrebserregers Sclerotinina sclerotiorum (lib.) de Bary durch Umweltfaktoren. (the influence of some environmental factors on the development of apothecia and ascospores of Sclerotinia sclerotiorum (lib.) de Bary). Zeitschrift für Pflanzenkrankheiten und Pflanzenschutz, 82, 101-108.

Makowski, D., Taverne, M., Bolomier, J., \& Ducarne, M. (2005). Comparison of risk indicators for sclerotinia control in oilseed rape. Crop Protection, 24, 527-531.

Morrall, R. A. A., Rude, S. V., Turkington, R. K., \& Kaminski, D. A. (1990). Sclerotinina stem rot of canola: Integrating chemical control with disease forecasting based on petal infestation. Canadian Journal of Plant Pathology, 11, 195 (Abstract).

Nordin, K., Sigvald, R., \& Svensson, C. (1992). Forecasting the incidence of Sclerotinia stem rot on spring sown rapeseed/die Vorhersage von Rapskrebs auf Sommerraps. Journal of Plant Diseases and Protection, 99, 245-255.

Pope, S. J., Varney, P. L., \& Sweet, J. B. (1989). Susceptibility of cultivars of oilseed rape to Sclerotinia sclerotiorum and the effect of infection on yield. Aspects of Applied Biology, 23, 451-456.

Reich, J. D., Alexander, T. W., \& Chatterton, S. (2016). A multiplex PCR assay for the detection and quantification of Sclerotinia sclerotiorum and Botrytis cinerea. Letters in Applied Microbiology, 62, 379-385.

Spitzer, T., Bilovsky, J., \& Kazda, J. (2017). Effect of fungicide application timing on Sclerotinia sclerotiorum infection rate and yield in winter oilseed rape. Gesunde Pflanzen, 69, 6772.

Taylor, A., Rana, K., Handy, C., \& Clarkson, J. P. (2018). Resistance to Sclerotinia sclerotiorum in wild Brassica species and the importance of Sclerotinia subarctica as a Brassica pathogen. Plant Pathology, 67, 433-444.

Turkington, T. K., Morrall, R. A. A., \& Gugel, R. A. (1991a). Use of petal infestation to forecast sclerotinia stem rot of canola. Evaluation of early bloom sampling 1985-90. Canadian Journal of Plant Pathology, 13, 50-59.

Turkington, T. K., Morrall, R. A. A., \& Rude, S. V. (1991b). Use of petal infestation to forecast sclerotinia stem rot of canola: The impact of diurnal and weather-related inoculum fluctuations. Canadian Journal of Plant Pathology, 13, 347-355.

Turkington, T. K., \& Morrall, R. A. A. (1993). Use of petal infestation to forecast sclerotinia stem rot of canola: The influence of inoculum variation over the flowering period and canopy density. Phytopathology, 83, 682-689.

Twengström, E., Sigvald, R., Svensson, C., \& Yuen, J. (1998). Forecasting Sclerotinia stem rot in spring sown oilseed rape. Crop Protection, 17, 405-411.

Ziesman, B. R., Turkington, T. K., Basu, U., \& Strelkov, S. E. (2016). A quantitative PCR system for measuring Sclerotinia sclerotiorum in canola (Brassica napus). Plant Disesae, 100, 984-990. 